Portland State University

PDXScholar

1983

\title{
One-third octave band augmented speech discrimination testing for cochlear impaired listeners
}

Dianne Heath

Portland State University

Follow this and additional works at: https://pdxscholar.library.pdx.edu/open_access_etds

Part of the Cognition and Perception Commons, and the Speech and Hearing Science Commons Let us know how access to this document benefits you.

\section{Recommended Citation}

Heath, Dianne, "One-third octave band augmented speech discrimination testing for cochlear impaired listeners" (1983). Dissertations and Theses. Paper 3320.

https://doi.org/10.15760/etd.3300

This Thesis is brought to you for free and open access. It has been accepted for inclusion in Dissertations and Theses by an authorized administrator of PDXScholar. Please contact us if we can make this document more accessible: pdxscholar@pdx.edu. 
AN ABSTRACT OF THE THESIS OF Dianne Heath for the Master of Science in Speech Communication presented November 23, 1983.

Title: One-Third Octave Band Augmented Speech Discrimination Testing for Cochlear Impaired Listeners

APPROVED BY MEMBERS OF THE THESIS COMMITTEE:
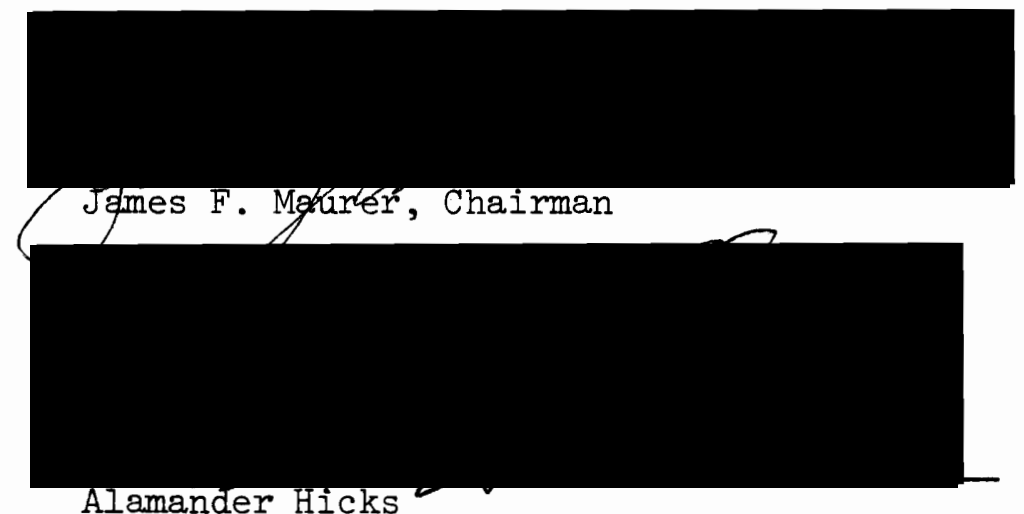

Alamander Hicks

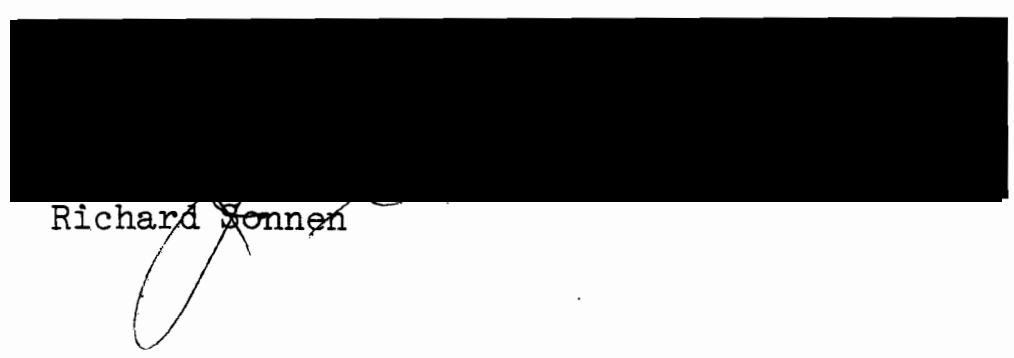

The purpose of this study was to investigate the effects of a $500 \mathrm{~Hz}$ and $3,150 \mathrm{~Hz}$ one-third octave band augmentation on the speech discrimination ability of listeners with cochlear hearing impairments. The results were analyzed both within the experimental group of subjects included in the present study and in comparison with data collected on a control group of normal hearing subjects reported earlier. 
The present investigation revealed the $500 \mathrm{~Hz}$ one-third octave band augmented word lists produced marked rollover in speech discrimination ability and a large standard deviation in subjects with cochlear hearing losses. On the other hand, the 3,150 $\mathrm{Hz}$ one-third octave band augmented speech test did not produce significant rollover in the subjects tested. The standard deviation observed in this condition was small, suggesting consistent performance among the subjects. Furthermore, there was no significant difference between the performance of the subjects in the present experimental group and the subjects in the control group on this task.

It was concluded that the high frequency augmentation demonstrates potential as a sensitive clinical speech tool to differentiate auditory sites of lesion. The results of the present study support the need for further research administering this frequency-specific augmented speech test to patients with confirmed retrocochlear lesions. 


\section{ONE-THIRD OCTAVE BAND AUGMENTED SPEECH DISCRIMINATION} TESTING FOR COCHLEAR IMPAIRED LISTENERS

by

Dianne Heath

A thesis submitted in partial fulfillment of the requirements for the degree of

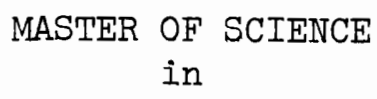

SPEECH

with emphasis in Speech Pathology

and Audiology

Portland State University

1983 
TO THE OFFICE OF GRADUATE STUDIES AND RESEARCH:

The members of the Committee approve the thesis of Dianne Heath presented on November 23, 1983.
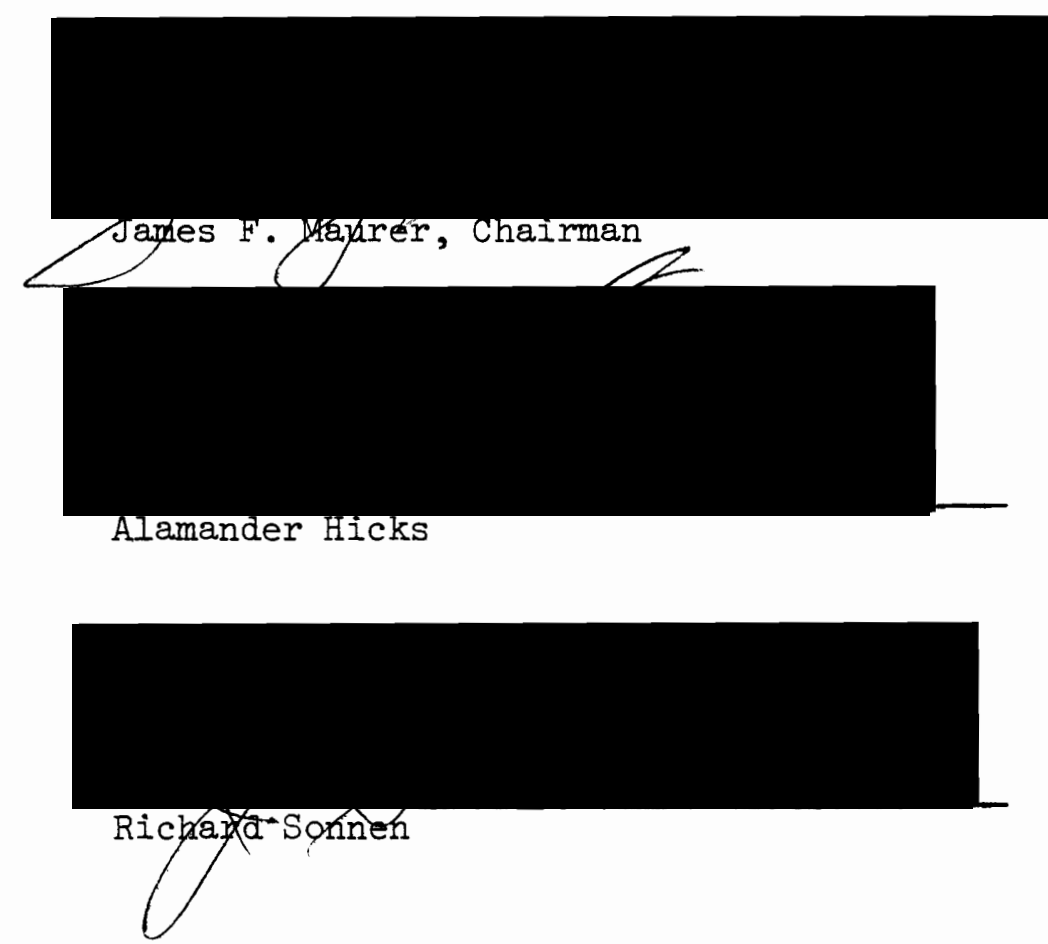

APPROVED :

Theodore G. Grove, Head, Department of Speech Communication

Stanley E. Rauch, Dean of Graduate Studies and Research 


\section{ACKNOWLEDGEMENTS}

I am greatly indebted to Dr. James F. Maurer, my academic advisor and thesis committee chairman, for his encouragement and guidance throughout this investigation. His time and talent were given freely to record the cassette tapes used in the research.

My gratitude goes to Dr. Al Hicks for his input in the study. His technical skill and advice made the project possible.

I would like to thank Dr. Richard Sonnen for serving on my thesis committee and offering his time and suggestions.

Finally, my special gratitude and appreciation go to Nancy Marie Bowen for supplying me with the data collected from her thesis, which formed the foundation for mine. Her suggestions were invaluable for the completion of this project. 
TABLE OF CONTENTS

PAGE

ACKNOWLEDGEMENTS

LIST OF TABLES .

LIST OF FIGURES

CHAPTER

I INTRODUCTION • • • • • • • • • • • • • • • I

II REVIEW OF THE LITERATURE • • • • • • • • • • • • • • 2

Sensorineural Hearing Loss and Speech Discrimination 2

Psychophysical Manifestations of Cochlear Impairment 4

Recruitment

Abnormally Wide Critical Bandwidths

Upward Spread of Masking

Differentiating Cochlear from Eighth Nerve Lesions

Using Performance-Intensity Function . . . • . 10

PURPOSE

III METHODS

Subjects

Procedures

Instrumentation . • . . . . . . . . . . . 18

Calibration . . . . . . . . . . . . . . 19

IV. RESULTS • • • • • • • • • • • • • • • • • . 
CHAPTER

PAGE

$\mathrm{V}$ DISCUSSIONS AND CONCLUSIONS • • • • • • • • • . . . 26

Implications for Further Research . . . . . . . 28

BIBLIOGRAPHY • • • • • • • • • • • • • • • • • 


\section{LIST OF TABLES}

TABLE

PAGE

I A Comparison of the Mean Percent Correct Scores and

Standard Deviations of the Experimental and Control

Groups for Each of the Four Listening Conditions . . . 24

II A Comparison of the Mean Percentage Difference Scores

and Standard Deviations Between the Experimental and

Control Groups for Each Augmented Listening

Condition . . . . . . . . . . . . . 25 


\section{LIST OF FIGURES}

FIGURE

1. Mean Thresholds of Subjects and Envelope Showing Range of Thresholds at Each Frequency . . . . . . 16 
CHAPTER I

INTRODUCTION

Speech audiometry is used as a basic clinical tool in the audiologic test battery. Traditionally, the purpose of speech audiometry has been to measure how complex speech sounds are received, integrated and transmitted through the peripheral auditory system.

The results of speech testing are used in the detection and estimation of degree of hearing impairment. Until quite recently, however, comparably little progress has been made in the quantitative application of speech audiometry to the differential diagnosis of the type and site of disorder causing sensorineural hearing loss. Therefore, the diagnostic value of traditional speech audiometry has remained limited due to performance variations within various diagnostic categories and overlapping results between patients otherwise differentiated by sites of lesion. The value of speech audiometry in differentiating specific sites of pathology within the auditory mechanism remains to be seen, although its potential is reflected by considerable ongoing research. 
CHAPTER II

REVIEW OF THE LITERATURE

Sensorineural Hearing Loss and Speech Discrimination

Individuals who sustain high frequency sensorineural hearing loss often experience difficulty understanding conversational level speech. In general, speech discrimination ability decreases progressively as the extent of the high frequency loss increases beyond 2,000 Hz (Liden, 1967; Bess and Townsend, 1977). In contrast, individuals with flat audiometric configurations generally experience little difficulty with word discrimination, scoring $80 \%$ or better on monosyllabic word tests (Iiden, 1967) until the hearing loss exceeds $50 \mathrm{~dB}$. Beyond the $50 \mathrm{~dB}$, a marked decrease in intelligibility has been observed (Thompson and Hoel, 1962).

A commonly accepted explanation for poor speech discrimination in cases of sensorineural hearing loss is that the audibility of many high frequency consonant sounds, which play an important role in distinguishing one word from another, is decreased or eliminated by the hearing loss (Bess and Townsend, 1977). Speech sounds differ in their build-up and decay characteristics, in duration, in total intensity and in the distribution of intensity with frequency (French and Steinberg, 1947). The energy of vowel sounds is carried mainly by the harmonics of the fundamental frequency of the speaker's voice and tends to be concentrated in one or more frequency regions. The consonant sounds contain components of higher frequency and lower intensity than the vowels. Moreover, the 
intensity tends to be scattered over the frequency region characteristics of each sound (French and Steinberg, 1947). The importance of the different regions of intensity and frequency to the intelligibility of speech has been investigated extensively (French and Steinberg, 1947; Pollack, 1948; Hirsh, Reynolds and Joseph, 1954; Chari, Herman and Danhauer, 1977).

Several studies have examined the correlation between speech discrimination scores and audiometric configuration (Sher and Owens, 1974; Bilger and Wang, 1976; Jerger and Hayes, 1977). The highest correlation has emerged for 2,000 and 3,000 Hz (Sher and Owens, 1974); therefore, these two frequencies appear to be more important for speech discrimination than other frequencies. Chari, Herman and Danhauer (1977) concluded from their study, which presented filtered speech through onethird octave bands, that intelligibility was highest for the bands centered at $2,000 \mathrm{~Hz}$ and relatively higher for the bands centered above than below $2,000 \mathrm{~Hz}$. These results are predictable since the important resonant regions for sibilant consonants occur above $2,000 \mathrm{~Hz}$. For example, for $/ S /$, the range is 2,000 to $4,000 \mathrm{~Hz} ; / \mathrm{s} /, 3,500 \mathrm{~Hz}$ and above; and /f/, between 6,800 and 8,400 Hz (Hughes and Halle, 1956).

LaCroix and Harris (1979) also demonstrated the critical contribution of 2,000 $\mathrm{Hz}$ on intelligibility. They compared the effect of distortion by acceleration, interruption and noise masking on intelligibility in subjects with sensorineural losses beginning at 2,000, 3,000 and 4,000 $\mathrm{Hz}$. The performance of subjects with hearing losses at 2,000 $\mathrm{Hz}$ was significantly poorer than normal hearing subjects and as the loss moved out from 3,000 to $4,000 \mathrm{~Hz}$, performance more closely approximated the normal hearing control group. 
Therefore, research has demonstrated high frequency sensorineural hearing loss can degrade speech intelligibility. The detrimental effects of sensory hearing loss on speech are also explained by the psychophysical functioning of the cochlear partition.

Psychophysical Manifestations of Cochlear Impairment

Poor speech perception by persons sustaining cochlear impairment results from reduced frequency analysis and loudness distortion (Evans, 1978; Scharf, 1978). The audiometric and psychophysical characteristics of cochlear pathology are recruitment of loudness and deterioration in speech discrimination as a consequence of widened critical bandwidths and increase in upward spread of masking.

\section{$\underline{\text { Recruitment }}$}

Loudness recruitment is consistently associated with disorders that affect the hair cells of Corti's organ, whereas it is characteristically absent in lesions of the eighth nerve and conductive losses (Hood and Poole, 1965). The essential feature of recruitment is an abnormal rapid increase in loudness that accompanies an intensity increase. Evans (1978) reports the cochlear nerve is comprised of approximately 30,000 fibers which represent overlapping narrow band linear filters. Each cochlear fiber is tuned to a restricted range of frequencies. Acoustic signals whose energies correspond to this range will evoke a rate of discharge of action potential spikes in individual cochlear nerve fibers. In a given frequency response area, the just discernable rate of discharge is the frequency threshold. The rate of discharge is related to intensity. The number of cochlear neuronal fibers stimulated depends on the sharpness of tuning of the cochlear fibers (Evans, 1975). In pathological cochleas, 
the tuning is broader than normal, resulting in elevated thresholds. The growth in number of active fibers (i.e. fibers stimulated) will be greater than in the normal ear. Lesions of the eighth nerve do not alter the tuning characteristics of the cochlear fibers, so no recruitment is present (Evans, 1975; Evans, 1978).

Recruitment contributes to perceptive distortion and loss of intelligibility by exaggerating loudness differences among the acoustical elements of speech (Hedgecock, 1955). Recruitment expands the difference in loudness between low-frequency higher intensity vowels and highfrequency low intensity consonants, and as a consequence speech suffers high frequency attenuation (Villchur, 1974). By simulating the effect of recruitment loudness in normal listeners, Villchur (1974) demonstrated that recruitment is a sufficient cause for loss of intelligibility. Clinically, recruitment is detected in loudness balance tests in which the patient compares the loudness of a tone in the impaired ear to the loudness of the same signal presented alternately to the normal ear (Fowler, 1937). In cases of bilateral hearing impairment, the patient makes an equal loudness judgment between two test frequencies in the same ear. Another method of measuring loudness recruitment utilizes difference limen for intensity. The recruiting ear has been found to detect abnomally small intensity changes at suprathreshold levels (Jerger, Shedd and Harford, 1959).

While recruitment is seen in the majority of cochlear lesions, it may also be observed in as many as 40 to 48 percent of patients with confirmed eighth nerve lesions (0lsen and Matkin, 1978). The overlap may occur because some patients with eighth nerve lesions may also sustain pre-existing cochlear damage with accompanying recruitment 
(Priede and Coles, 1976).

Abnormally Wide Critical Bandwidths

The normal ear separates a complex sound into narrow bands of frequencies called critical bands. As the width of a band of noise is increased, its total sound pressure remains constant until the critical band is exceeded, at which point the loudness level increases with increasing bandwidth (Scharf, 1978). The total loudness experienced is the predictable sum of the component loudnesses of all the critical bands (Scharf and Hellman, 1966). Experimental methods of measuring the width of the critical band have utilized wide-band masking, two-tone masking, loudness summation and lateralization of tone bursts (Scharf and Meiselman, 1977). The width of the critical band varies with frequency and is wider with increasing frequency.

It has also been suggested the critical bandwidth is wider at higher intensity levels than at low intensity levels (Evans, 1977). Scharf and Meiselman (1977) reported the width is invariant up to about $80 \mathrm{~dB}$ SPL, beyond which it increases.

The cochlear impaired auditory system does not appear to analyze auditory input into critical bands in the same manner as the normal ear. Loudness does not increase when the critical bandwidth is exceeded (Scharf and Hellman, 1966; Scharf, 1978), even when the noise spectrum covers 6 or 7 normal critical bands (Martin, 1974). Scharf (1978) suggests that listeners with cochlear impairment have normal sized critical bands at lower frequencies and progressively abnormally widened critical bands at higher frequencies, corresponding with elevated thresholds. Evans (1978) reports bandwidth does not increase in a linear manner with level of threshold elevation. For elevations up to about $40 \mathrm{~dB}$, the increase 
in bandwidth is relatively small, whereas for greater elevations the bandwidth increases rapidly up to a factor of 5 for losses of the magnitude of $80 \mathrm{~dB}$. A substantial loss of speech discrimination ability is not expected until threshold is elevated at least $40 \mathrm{~dB}$ above normal (Evans, 1978; Priede and Coles, 1976).

Critical bands appear to be measures of the effective bandwidth of the filtering ability of the ear at various frequencies. Evans (1975) proposes a two filter hypothesis to explain this phenomenon. The first filter corresponds to the basilar membrane filter, which is broadly tuned. The second filter, more sharply tuned, may involve some sort of interaction between the inner and outer hair cells.

The width of the critical band denotes the bandwidth of frequency integration (De Boer and Bouwmeester, 1974). An abnormally widened critical band results in a deterioration in frequency resolving power, which occurs in the normal cochlear partition. Frequency selectivity, the ability of the auditory system to analyze or separate out the individual components of a complex signal, is important for speech perception, pitch perception and frequency discrimination (Hoekstra and Ritsma, 1977). Subjects with cochlear impairment have been found to exhibit impaired frequency resolving capability (Pick, Evans and Wilson, 1977). Frequency selectivity ability has been noted to decrease by factors of 5 to 10 (Evans, 1978) and prevents proper formant separation in speech. For formant relationships to be adequately analyzed, the spacing between the formants must exceed the critical bandwidth of the auditory filter (Evans, 1978). Harris, Haines and Myers (1955) reported that the range through which an ear can summate energy is shorter for recruiting ears than for normal ears. From this, Simon (1963) hypothesized the corresponding 
bandwidth is increased for frequencies where recruitment is present; the width of the critical band increases as the time through which temporal summation can occur decreases. He found the width of the critical band is, indeed, greater at frequencies exhibiting recruitment than corresponding frequencies in normal hearing listeners.

Bandwidth is also influenced by signal duration. Gengel (1973) demonstrated that for both normal hearing and sensorineural hearing impaired subjects, bandwidth increases as signal duration decreases from $500 \mathrm{msec}$ to $50 \mathrm{msec}$.

\section{Upward Spread of Masking}

Psychoacoustic tuning curves are obtained from values of a tonal masker required to just mask a probe of a constant intensity and frequency of the masker. The results are plotted as minimum masker intensity needed to mask the probe as a function of masker frequency (Wightman, McGee and Kramer, 1977). Tuning curves bear a resemblance to the frequency response of single auditory fibers and consequently provide information on frequency selectivity (Leshowitz and Lindstrom, 1977).

Tuning curves represent the spread of masking and studies investigating the spread of masking describe masking effects as the amount of threshold shift produced by a masker. Comparisons of masking in normal and impaired ears have shown that the cochlear impaired ear exhibits greater than normal spread of masking, both above and below the frequency band of masking sound (Jerger, Tillman and Peterson, 1960; Leshowitz and Lindstrom, 1977). It has also been reported that the ear sustaining cochlear pathology produces asymmetrical masking patterns. In low frequency regions where thresholds are within normal limits, masking effects are similar to normal ears, whereas excessive masking occurs in 
higher frequencies which exhibit threshold elevation (De Boer and Bouwmeester, 1974; Leshowitz and Lindstrom, 1977). For example, a $68 \mathrm{~dB}$ masker at 4,800 Hz was found to be sufficient to mask a $75 \mathrm{~dB} 5,400 \mathrm{~Hz}$ tone (Leshowitz and Lindstrom, 1977).

The pronounced upward spread of masking has been found to have a detrimental effect on speech discrimination. Pollack (1948) used high pass (above $2,500 \mathrm{~Hz}$ ) and low pass (below $350 \mathrm{~Hz}$ ) filters and presented speech at high intensity levels. Scores were higher with high pass filtering conditions than with the low pass condition. Furthermore, speech intelligibility was reduced when low pass frequencies were added to the high pass frequencies. Only at low intensity levels did the low frequencies make a positive contribution to intelligibility.

Using subjects with sensorineural hearing losses, Danaher and Pickett (1975) presented the first and second formants $\left(F_{1}\right.$ and $F_{2}$ ) of the synthesized vowels /a/ and / $/$ / in three conditions; first, simultaneously to both ears, next $F_{2}$ alone, and finally, they separated the formants by presenting $F_{1}$ to one ear and $F_{2}$ to the opposite ear. Speech discrimination ability was poorer with both formants presented together than with $F_{1}$ eliminated. Separating the formants improved the scores over the simultaneous condition, but scores were still poorer than with $\mathrm{F}_{2}$ presented alone. These results suggest that the low frequency formant produces two different types of masking. When the vowel formants are presented to the same ear, an upward spread of masking occurs. The second type appears to involve central masking since it occurs when $\mathrm{F}_{1}$ and $F_{2}$ are heard in opposite ears.

A strong correlation between additivity of masking and frequency discrimination in listeners with hearing loss due to cochlear damage has 
been reported (Gengel, 1973; Scharf, 1978). In regions of threshold elevation, as much as a 10-fold decrease in frequency discrimination has been observed (Leshowitz, Lindstrom and Zurek, 1976).

\section{Differentiating Cochlear from Eighth Nerve Lesions Using}

\section{Performance-Intensity Function}

Speech discrimination loss is generally proportional to the hearing loss in cochlear cases, whereas it is disproportionately great in neural cases (Priede and Coles, 1976; Jerger and Hayes, 1977). However, speech discrimination scores with word items delivered at comfortable listening levels have not successfully differentiated cochlear from eighth nerve disorders. Priede and Coles (1976) compared scores of subjects with cochlear pathology and confirmed eighth nerve lesions and found a 10 percent overlap. Jerger and Jerger (1971) demonstrated that scores obtained on phonetically balanced word lists presented at high intensity levels, referred to as performance intensity (PI) function, differed significantly between patients with retrocochlear disorders and those with cochlear impairments. In the latter case, the function rose to a maximum ( $P B \max$ ) level and then either flattened or decreased moderately as the intensity of the speech signal was increased. Patients sustaining eighth nerve lesions, in contrast, showed a substantial decline, referred to as "rollover", in speech discrimination scores as the intensity level was increased beyond $P B \max$.

The rollover index is calculated by determining the lowest score ( $P B \min$ ) at the highest intensity tolerated and the maximum score ( $P B \max$ ) and inserting the figures in the formula $\frac{P B_{\max }-P B_{\min }}{P B_{\max }}$. Jerger and Jerger compared the articulation functions of subjects who had cochlear 
and retrocochlear lesions and found three patterns. The cochlear group rarely showed indices above .30; eighth nerve lesion subjects displayed marked (.40) to complete (1.00) rollover; and persons with brain stem and temporal lobe lesions overlapped both the eighth nerve and cochlear groups with indices of 0 to 1.00 in the ear contralateral to the affected side. Priede and Coles (1976), on the other hand, reported the rollover effect occurred in both patients with Meniere's disease and eighth nerve lesions. They concluded the rollover effect, as currently measured, does not provide a satisfactory distinction between the majority of sensory and neural cases.

A relatively new method of examining rollover has been investigated by Maurer, et al. (1981) who employed one-third octave band-pass filters to augment either low frequency ( $500 \mathrm{~Hz}$ band-pass) or high frequency $(3,150 \mathrm{~Hz}$ band-pass) portions of monosyllabic words presented to normal hearing subjects. Large standard deviations were reported under the low band-pass augmentation. Smaller standard deviations were observed in the high frequency band-pass augmented condition; nevertheless, the effect of frequency augmentation on speech discrimination ability was not firmly established and further research in the area was implied.

More recently, Bowen (1982), using the same 500 and $3,150 \mathrm{~Hz}$ onethird octave band-pass filters, investigated the effects of frequency and intensity on the speech discrimination ability of normal hearing listeners. The filtered portions of monosyllabic words were augmented from 5 to $55 \mathrm{dBHL}$ above the intensity level of the unfiltered portions. Both filtering conditions were found to reduce speech discrimination ability. The $500 \mathrm{~Hz}$ low frequency augmented condition produced a significant rollover in speech discrimination scores with increasing 
intensity. As in the Maurer, et al. study, statistical analysis of the results revealed large standard deviations. The high frequency condition, on the other hand, produced small standard deviations at all presentation levels which supports its potential as a clinical diagnostic test.

The theoretical rationale for an augmented speech test to differentiate cochlear site of lesion may be derived from the three psychoacoustic parameters of cochlear pathology described earlier that appear to strongly influence peripheral processing of speech, specifically

1) recruitment, which has been noted to exaggerate loudness differences among high intensity vowels and low intensity consonants, thereby degrading speech intelligibility; 2) widened critical bandwidths, which prevents formant separation in speech due to impaired frequency resolving capability, especially at high intensity levels above $80 \mathrm{~dB}$ SPL; and 3) upward spread of masking, which appears to be pronounced in cases of cochlear pathology and causes low frequency components of speech to interfere with or mask the audibility of high frequency components.

The present study investigates the responses of individuals with cochlear hearing losses. In light of the psychophysical manifestations of cochlear impairment, it is proposed that the performance of listeners with sensory losses will differ significantly from that of normal hearing subjects reported in the Bowen (1982) study in the low frequency augmentation listening task. Increasing the intensity of low frequency ( $500 \mathrm{~Hz}$ ) one-third octave band filtered portions of monosyllabic words is expected to have a more pronounced detrimental effect on speech discrimination as a result of upward spread of masking. In contrast, augmenting high frequency $(3,150 \mathrm{~Hz})$ one-third octave band filtered portions of words should enhance speech discrimination ability by 
permitting the perception of high frequency consonants which are important to speech intelligibility. This will result in performance scores comparable to that of normal hearing subjects. The clinical importance of this study is that it will investigate a non-invasive, relatively expedient test which may provide an additional basis for differentiating sites of auditory lesions.

\section{PURPOSE}

The purpose of this study is to investigate the speech discrimination ability of individuals with cochlear hearing losses in response to speech stimuli which have been augmented by one-third octave band filters centered at $500 \mathrm{~Hz}$ and $3,150 \mathrm{~Hz}$ and presented at high intensity levels.

The following results are hypothesized:

1. The scores of word lists presented through a $500 \mathrm{~Hz}$ one-third octave band filtered augmentation to subjects with cochlear hearing losses will be lower than the maximum scores obtained ( $P B \max$ ) under normal listening conditions.

2. The scores of word lists presented through a 3,150 Hz one-third octave band filtered augmentation to subjects with sensory losses will be comparable to the maximum scores obtained under normal listening conditions.

3. The scores of word lists presented to cochlear impaired subjects through a $500 \mathrm{~Hz}$ one-third octave band filtered augmentation will be lower than the scores obtained by normal hearing subjects under the same listening conditions.

4. The scores of word lists presented through a 3,150 Hz one-third octave band filtered augmentation to subjects with cochlear hearing losses will not ditterer significantly from the scores obtained by normal hearing 
subjects under the same listening conditions. 


\section{METHODS}

$\underline{\text { Subjects }}$

Twenty subjects under the age of 60 years with cochlear hearing impairment were selected from the patients seen in the Audiology Section of the Portland Veterans Administration Medical Center. The determination of cochlear impairment was based on the following criteria:

1. Thresholds of $\leq 25 \mathrm{dBHL}$ in at least two frequencies above $1,000 \mathrm{~Hz}$.

2. The absence of an air-bone gap greater than $10 \mathrm{dBHL}$ as measured at frequencies from 250 to $4,000 \mathrm{~Hz}$.

3. The presence of loudness recruitment as indicated by a score of $70 \%$ or higher on the Short Increment Sensitivity Index test in at least one frequency.

4. The absence of significant ( $>30 \mathrm{dBHL})$ tone decay according to the Rosenberg Tone Decay Test.

5. Clinical history and medical findings consistent with cochlear disorder.

\section{Procedures}

All subjects were given an audiologic evaluation utilizing standard clinical procedures. Only one ear per subject was used for the experimental test conditions. The ear with the greater cochlear impairment was 


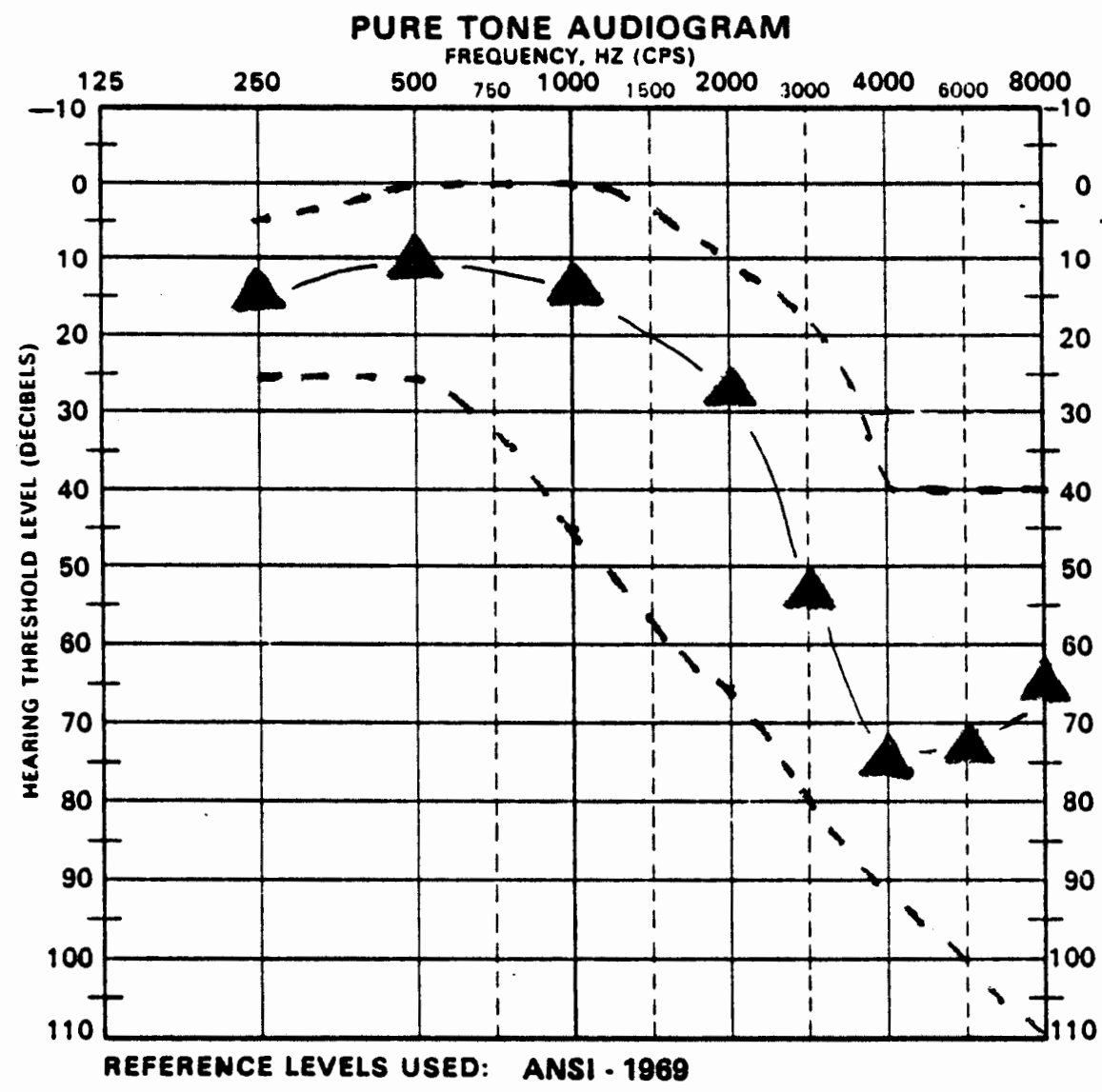

Fig. 1. Mean thresholds of subjects and envelope showing range of thresholds at each frequency. 
selected as the test ear. If no significant difference existed between the ears, the ear to be tested was randomly chosen. Because of possible earedness effect, the sample was divided approximately equally with respect to ear tested.

The subjects were seated in a double-walled suite and wore earphones. They were instructed to write down on the answer sheets provided each recorded word exactly as they heard it and were encouraged to guess if they were uncertain of a word.

In order to insure that the experimental data reflected only the test ear responses, contralateral masking was employed during all listening conditions. Wide band masking noise (speech noise) was presented to the nontest ear at a level 20 dBHL below the test ear stimuli.

Each subject was presented four pre-recorded lists of monosyllabic words (Campbell, 1965), 50 words each, delivered in the following conditions :

1. Most comfortable listening level (MCL), unfiltered.

2. Low pass ( $500 \mathrm{~Hz}$ one-third octave band filtered) augmentation.

3. High pass $(3,150 \mathrm{~Hz}$ one-third octave band filtered) augmentation.

4. Whole word augmentation, unfiltered. Under each one-third octave band pass listening condition ( 2 and 3 above), the left channel output (unfiltered word) was set at MCL, and the output from the right channel (the augmented filtered portion of the word) was delivered at $5 \mathrm{dBHL}$ below the reported uncomfortable listening level (UCL). These two intensity disparate signals were fed to the same ear simultaneously by one earphone, producing an augmented filtered word. The unfiltered 
augmentation ( 4 above) was delivered at 5 dBHL below UCL.

To avoid any possible effect of presentation order on the test results, the order of experimental test conditions presented was randomly varied. In addition, to prevent the possible intervening effects of temporary threshold shift, subjects were given a rest period of at least two minutes between each test condition.

A brief set of recorded instructions was included before each experimental condition followed by five practice words. Each of the augmented word lists was preceded by a different set of practice items which were augmented according to the experimental condition they preceded.

\section{Instrumentation}

The stimulus tape used for the present study was the same tape used in the Bowen (1982) study described earlier. The tape consisted of two 25 monosyllabic word lists (lists $\mathbb{N}$ and P; Campbell, 1965).

The method of recording has been reported by Bowen as follows:

In order to avoid the learning effect created by a serial presentation of the same word list for three experimental conditions, the two 25-word lists were combined and the 50 words were randomly ordered three times by means of a table of random numbers (Freund, 1973). The three randomly ordered 50-word lists were spoken by a male with a general American dialect through the microphones of a dual channel audiometer (Maico, Model MA 24B). The output from the right channel to the audiometer was fed through a one-third octave filter (Bruel and Kjaer, Model 1616) with a rejection rate of $50 \mathrm{~dB} /$ octave, where only the selected frequency band was fed to the right channel of a stereo cassette recorder (Hitachi, Model D 90-S). The output from the left channel of the audiometer was fed through directly to the left channel of the cassette recorder without filtering. Thus, the stereo cassette tape contained an unfiltered version of each word on the left channel, coincident with the one-third octave spectral information recorded on the right channel. This master tape recording was made utilizing a high bias (70/ $\mu \mathrm{sec})$, low noise metal tape (Maxell, MX C-60). For each of the 
augmented test conditions, the right and left channels were always delivered to the same ear simultaneously, resulting in an augmented presentation.

This two channel recording technique allowed independent manipulation of the intensity relationship between the word and its one-third octave augmentation component. For the unfiltered augmented test condition, the stimulus words were recorded through the audiometer directly onto both channels of the stereo cassette tape recorder, by-passing the one-third octave filter. Right and left channels containing this unfiltered augmented word list were also delivered simultaneously to the same ear.

The three experimental conditions were rerecorded six times by means of a second cassette recorder (Technics, Model RS-263AUS) and a low noise, high bias tape (Maxell, UDXI II C-90). This allowed all possible combinations of presentation order for each experimental condition. 1

For the present study, a stereo cassette tape recorder (Dual,

Model C939) was connected to a dual channel audiometer (Grason Stadler, Model 1701), so that the right channel controlled the output from the right channel of the cassette recorder and the left channel controlled the output from the left channel of the cassette recorder. The output from the audiometer was patched through a double-walled acoustic suite (Industrial Acoustics Company, Model 1204) to the test ear via a single earphone from a pair of standard audiometric headphones (Telephonics, Model TDH 49) mounted in foam rubber cushions (Acoustic Research, Model MX 41). The second earphone delivered wide band masking noise from a masking generator (Grason Stadler, Model 1285) to the nontest ear.

\section{Calibration}

The output at the earphones and bone oscillator was electroacoustically calibrated to reflect current ANSI (1969) standards prior to testing. A prerecorded segment of speech spectrum noise was used to calibrate the

IBowen, N.M., "One-Third Octave Band Augmented Speech Discrimination Testing for Normal Hearing Listeners." Unpublished Master's Thesis, Portland State University (1982) pp. 34 and 36. 
speech circuit. In addition, a speech spectrum calibration signal was recorded on the stimulus tape preceding each experimental condition to allow VU monitor adjustments prior to the presentation of each word list. 


\section{CHAPTER IV}

\section{RESULTS}

The purpose of this study was to investigate the effects of a $500 \mathrm{~Hz}$ and 3,150 $\mathrm{Hz}$ one-third octave band augmentation on the speech discrimination ability of listeners with cochlear hearing losses. The experimental group consisted of twenty adult males with hearing losses consistent with cochlear pathology. Written responses to monosyllabic word stimuli delivered within each of the four listening conditions were analyzed. The conditions, again, were 1) most comfortable listening level, unfiltered, 2) low pass augmentation, 3) high pass augmentation, and 4) whole word augmentation, unfiltered.

The raw performance data (percent correct scores) for the four listening conditions were analyzed statistically and the means and variances were determined for each condition. These scores were compared first within this group of subjects (experimental group), and second, in comparison with the normal hearing subjects (control group) reported by Bowen (1982). In the experimental group, the comparison of the mean speech discrimination scores for the four listening conditions demonstrated significantly poorer performance during the low pass, $500 \mathrm{~Hz}$ augmented listening condition ( $43.6 \%$ ) than during the other conditions. The performance scores recorded for the other conditions were $89 \%$ for the high pass, 3,150 Hz augmentation, $92.7 \%$ for the most comfortable listening level, and $87.1 \%$ for the unfiltered augmentation. The standard deviation 
for the $500 \mathrm{~Hz}$ augmentation was also much greater than for the other conditions. The raw data for these four experimental listening conditions were subjected to a t-test of dependent or correlated data (Bruning and Kintz, 1977). The subjects' performance on the $500 \mathrm{~Hz}$ augmented condition differed significantly $(p<.005)$ from each of the other conditions. That is, there was no statistically significant difference between scores for the $3,150 \mathrm{~Hz}$ augmented condition and either MCL or the unfiltered augmented condition.

In the second phase of statistical analysis, the raw data for each listening condition in the experimental group was compared with the performance scores of the control group according to a t-test for difference between two independent means. In the Bowen (1982) study, which utilized 36 normal hearing subjects, the augmented word lists were presented at intensity disparity levels between the filtered portion of the word and the unfiltered whole word which ranged from $5 \mathrm{dBHL}$ to $55 \mathrm{dBHL}$. Bowen's results indicated that speech discrimination ability was affected only slightly at the $5 \mathrm{dBHL}$ disparity level, and performance was more significantly degraded at the $45 \mathrm{dBHL}$ and $55 \mathrm{dBHL}$ disparity levels, especially for the $500 \mathrm{~Hz}$ augmented condition. These results were taken into consideration in determining the disparity levels between the filtered and unfiltered presentations for the present study. In addition, the thresholds of discomfort were generally lower for the cochlear impaired subjects than for the normal hearing subjects due to recruitment, which is often associated with cochlear lesions. This, in turn, reduced the range between most comfortable listening level (the intensity level of the whole word presentation) and 5 dBHL below the uncomfortable listening level (the intensity level of the filtered portion of the word). 
As a result, the intensity disparity levels between the augmented portion of the word and the unfiltered word for the present study ranged from $15 \mathrm{dBHL}$ to $35 \mathrm{dBHL}$, with an overall mean disparity level of $25 \mathrm{dBHL}$. The data from the present experimental group was statistically compared with performance scores from 18 of the 36 subjects in Bowen's (1982) control group who presented disparity levels ranging from 15 aBHL to $35 \mathrm{dBHL}$. Thus, the listening conditions which were common to both groups consisted of the $500 \mathrm{~Hz}$ augmentation, the 3,150 Hz augmentation and the unfiltered augmentation. The t-test for difference between independent means revealed there was a statistically significant difference $(p<.005)$ in the performance of the experimental and the control groups for each of the three augmented listening tasks compared. See Table I.

The above analysis did not take into account the actual changes in speech discrimination performance. It was reasoned the statistical analysis demonstrated a difference because the mean score attained at MCL by the experimental group, while still within the range of normal speech discrimination ability (90-100\%), was lower than the mean score recorded by the normal hearing group. Therefore, the difference between the score recorded at MCL and the score obtained on each augmented task was calculated for each subject and these difference scores analyzed. A t-test for difference between independent means revealed that the variances between the two groups' difference scores were not statistically significant on the 3,150 $\mathrm{Hz}$ augmentation and the unfiltered augmentation. However, there was a statistically significant difference $(p<.005)$ on the $500 \mathrm{~Hz}$ augmented word lists. See Table II. 


\section{TABLE I}

A COMPARISON OF THE MEAN PERCENT CORRECT SCORES AND STANDARD DEVIATIONS OF THE EXPERIMENTAL AND CONTROL GROUPS FOR EACH OF THE FOUR LISTENING CONDITIONS.

Listening

Condition
Mean Percentage

of Words Correct
Standard

Deviation

$500 \mathrm{~Hz}$

$1 / 3$ octave

Experimental

43.6

82.8

14.94

band pass

Control

15.66

$3,150 \mathrm{~Hz}$

$1 / 3$ octave

Experimental

89.0

5.08

band pass

Control

96.6

3.12

Unfiltered

Experimental

92.7

Control

98.7

6.84

MCL

Experimental

87.1 Control

98.0

2.37

Unfiltered whole word augmentation

7.98

3.21

Differences between the mean scores between the experimental and control groups in all listening conditions were statistically significant ( $p<.005)$. 
A COMPARISON OF THE MEAN PERCENTAGE DIFFERENCE SCORES AND STANDARD DEVIATIONS BETWEEN THE EXPERIMENTAL AND CONTROL GROUPS FOR EACH AUGMENTED LISTENING CONDITION.

Listening

Condition
Mean Percentage

Difference Scores
Standard

Deviation

\section{*MCL $-500 \mathrm{~Hz}$}

1/3 octave band pass

MCL-3, $150 \mathrm{~Hz}$

$1 / 3$ octave

band pass

MCL-whole word

augmentation
Experimental

Control

49.1

15.9

13.86

15.13
Experimental

Control

Experimental

Control
5.1

3.4

3.64

2.81

6.2

2.4

Difference scores were obtained by subtracting the mean percentage of words correct on each augmented listening condition from the mean percentage of words correct recorded at MCL.

* Difference between the mean scores of experimental and control groups was statistically significant $(p<.005)$. 
CHAPTER V

DISCUSSIONS AND CONCLUSIONS

The results from the present study indicate that in a population of subjects sustaining sensory hearing losses, a high frequency augmentation of speech test material does not produce rollover in discrimination scores. On the other hand, low frequency augmentation with the same population degrades speech discrimination ability beyond the .30 index which constitutes significant rollover in conventional rollover tests. The low frequency augmentation results differed significantly from both the other listening tasks within the same sample and compared to normal hearing subjects. These results were predictable based on the psychoacoustic parameters described earlier of recruitment, widened critical bands and upward spread of masking. In persons sustaining cochlear lesions, low frequency augmentation greatly degrades speech discrimination ability by amplifying the vowels which, in turn, masks the audibility of high frequency consonants. The performance among subjects on this task also varied as evidenced by a large standard deviation. The potential application of a low frequency augmented word list as a clinical tool to differentiate auditory sites of lesion appears limited because of performance variances both in the normal hearing control group and in the present experimental group. On the other hand, the high frequency augmentation produced a relatively small standard deviation which suggests more consistent 
performance among subjects in this sample and a reasonable basis for comparison with normal hearing subjects. The performance of a sensory impaired population on this task appears to be comparable to the performance of a normal hearing population when degradation of speech discrimination ability from $P B \max$ is considered. Further, within the experimental group, a comparison of the mean scores recorded on the high frequency augmentation and unfiltered augmentation reveals overall better performance and smaller standard deviations on the high frequency augmented list than on the unfiltered augmented list, or conventional rollover test. While these differences in mean scores were not statistically significant, they do appear to warrant further consideration.

It appears that persons sustaining sensory losses show some rollover when the whole word is augmented, which may explain overlap reported in the past between patients with eighth nerve and cochlear lesions. Since the subjects in this study demonstrated less degradation of speech discrimination scores on the high frequency augmented word list than on the conventional rollover test, the former appears to possess potential as a more sensitive diagnostic speech tool with less overlap than conventional rollover tests to differentiate cochlear from retrocochlear sites of lesion. In other words, the addition of frequency distortion to the existing intensity distortion enhances the diagnostic value of the test.

Jerger's index of $30 \%$ deteriortation in speech discrimination from

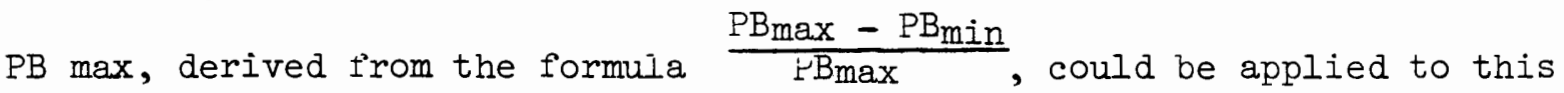
frequency-specific rollover test. Further study may refine this equation for performance scores associated with this task. Nevertheless, a score indicating rollover on this test could rule out cochlear pathology as the 
underlying cause of hearing loss. The exception to this statement is cochlear hearing loss due to Meniere's disease. The subjects in this study were selected who demonstrated high frequency sloping audiometric configurations consistent with noise trauma. Patients with Meniere's disease involving low frequency hearing loss were excluded based on the findings by Priede and Coles (1976) described earlier who reported the rollover effect occurred in both patients with Meniere's disease and eighth nerve lesions. Additional research administering these one-third octave band augmented word lists to subjects with flat losses and apical losses would provide useful data to compare with the present findings. In summary, the $500 \mathrm{~Hz}$ one-third octave band augmented word lists presented to subjects with cochlear hearing losses produced marked rollover in speech discrimination ability and a large standard deviation within the group. These findings limit the usefulness of this test to differentiate cochlear from retrocochlear sites of leasion. The performance of the same subjects on a 3,150 $\mathrm{Hz}$ one-third octave band augmented speech test was comparable to the findings reported by Bowen (1982) on normal hearing subjects. Since no significant difference was found between cochlear impaired and normal hearing subjects in this condition, a recorded augmented word list of this type could conceivably be included in a clinical test battery to differentiate retrocochlear sites of lesion. However, further research is warranted before it can be accepted as a viable diagnostic test.

\section{Implications for Further Research}

The present study was concerned with collecting normative data for a cochlear impaired population utilizing frequency-specific augmented 
speech tests. This data, combined with the data collected on a normal hearing population, will provide a basis from which the performance of a third population, subjects with confirmed retrocochlear lesions, can be compared. The goal is to develop a clinical tool consisting of frequencyspecific augmented word lists which will be more sensitive than conventional rollover tests for differentiating the sites of auditory lesions.

An additional focus tor further research could be the relationship between degree and slope of high frequency sloping hearing losses and speech discrimination ability on frequency augmented word lists. Other types of cochlear losses, such as flat losses due to Meniere's disease, could be investigated using these frequency distorted word lists. 


\section{BIBLIOGRAPHY}

Bess, F.H. and Townsend, T.H., "Word Discrimination for Listeners with with Flat Sensorineural Hearing Losses," JSHD, 42:232-7, 1977.

Bilger, R.C. and Wang, M.D., "Consonant Confusions in Patients with Sensorineural Hearing Loss, " JSHR, 19:718-48, 1976.

Bowen, N.M., "One-Third Octave Band Augmented Speech Discrimination Testing for Normal Hearing Listeners." Unpublished Master's Thesis, Portland State University, 1982.

Bruning, J.L. and Kintz, B.L., Computational Handbook of Statistics, Glenview: Scott, Foresman and Company, 1977.

Campbell, R.A., "Discrimination Test Word Difficulty," JSHR, 8:13-22, 1965.

Chari, N.C., Herman, G. and Danhauer, J.I., "Perception of One-Third Octave Band Filtered Speech," JASA, 61:576-80, 1977.

Danaher, E.M. and Pickett, J.M., "Some Masking Effects Produced by LowFrequency Vowel Formants in Persons with Sensorineural Hearing Loss," JSHR, 18:261-71, 1975.

De Boer, E. and Bouwmeester, J., "Critical Bands and Sensorineural Hearing Loss," Audiology, 13:236-59, 1974.

Evans, E.F., "The Sharpening of Cochlear Frequency Selectivity in the Normal and Abnormal Cochlea," Audiology, 14:419-42, 1975.

Evans, E.F., "Frequency Selectivity at High Signal Levels of Single Units in Cochlear Nerve and Cochlear Nucleus." In Psychophysics and Physiology of Hearing, Evans, E.F. and Wilson, J.P. (eds.), London: Academic Press, 1977.

Evans, E.F." "Perlpheral Auditory Processing in Normal and Abnormal Ears: Physiological Considerations for Attempts to Compensate for Auditory Deficits by Acoustic and Electrical Prosetheses." In Sensorineural Hearing Impairment and Hearing Aids, Ludvigsen, $C$. and Barford, J. (eds.), Scand. Audiol. Suppl., 6:9-47, 1978.

Fowler, E.P., "Measuring the Sensation of Loudness," Archives Otolaryngol., 26:514-21, 1937. 
French, N.R. and Steinberg, J.C., "Factors Governing the Intelligibility of Speech Sounds," JASA, 19:90-119, 1947.

Freund, J.E., Modern Elementary Statistics. Englewood Cliffs: PrenticeHall, Inc., 1973.

Gengel, R.W., "Temporal Effects in Frequency Discrimination by HearingImpaired Listeners," JASA, 54:11-15, 1973.

Harris, J.D., Haines, H.L. and Myers, C.K., "Recruitment, Pitch Tests and Speech-Tone Hearing Discrepencies," Archives of Otolaryngol., $62: 66-70,1955$.

Hedgecock, L.D., "The Measurement of Auditory Recruitment," Archives of Otolaryngol., 62:515-27, 1.955.

Hirsh, I.J., Reynolds, E.G. and Joseph, M., "Intelligibility of Different Speech Materials," JASA, 26:530-8, 1.954.

Hoekstra, A. and Ritsma, R.J., "Perceptive Hearing Loss and Frequency Selectivity." In Psychophysics and Physiology of Hearing, Evans, E.F. and Wilson, J.P. (eds.), London: Academic Press, 1977.

Hood, J.D. and Poole, J.P., "Tolerable Limit of Loudness: Its Clinical and Physiological Significance," JASA, 40:47-53, 1965.

Hughes, G.W. and Halle, M., "Spectral Properties of Fricative Consonants," JASA, 28:303-10, 1956.

Jerger, J., Shedd, J., and Harford, E., "On the Detection of Extremely Small Changes in Sound Intensity," Archives of Otolaryngol., 69:200-11, 1959.

Jerger, J.F., Tillman, T.W. and Peterson, J.L., "Masking by Octave Bands of Noise in Normal and Impaired Ears," JASA, 32:385-90, 1960.

Jerger, J.F. and Jerger, S., "Diagnostic Significance of PB Word Function," Archives of Otolaryngol., 93:573-80, 1971.

Jerger, J.F. and Hayes, D., "Diagnostic Speech Audiometry," Archives of Otolaryngol., 103:216-22, 1977.

LaCroix, P.G. and Harris, J.D., "Effects of High-Frequency Cue Reduction on the Comprehension of Distorted Speech," JSHD, 44:236-46, 1979.

Leshowitz, B., Lindstrom, R. and Zurek, P., "Measurements of Frequency Selectivity in Listeners with Sensorineural Hearing Loss," JASA, Vol. 59, Suppl. No. 1, S2-S3, 1976.

Leshowitz, B. and Lindstrom, R., Measurement of Non-Linearities in Listeners with Sensorineural Hearing Loss." In Psychophysics and Physiology of Hearing, Evans, E.F. and Wilson, J.F. (eds.), London: Academic Press, 1977. 
Liden, G., "Undistorted Speech Audiometry." In Sensorineural Hearing Processes and Disorders, Graham, A.B. (ed.), Boston: Little, Brown and Company, 1967 .

Martin, M.C., "Critical Bands in Sensorineural Hearing Loss," Scand. Audiol., $3: 133-40,1974$.

Maurer, J.F., Hicks, A. and Bowen, N.M., "A Test for Speech Discrimination Function Utilizing Frequency Specific Auditory Augmentation."

Unpublished Research, Grant \#90-050-5801, Portland State University, 1981.

Olsen, W.O. and Matkin, N.D., "Differential Audiology." In Audiological Assessment, Rose, D.E. (ed.), Englewood Cliffs: Prentice-Hall, Inc., 1978.

Pick, G.F., Evans, E.F. and Wilson, J.P., "Frequency Resolution in Patients with Hearing Loss of Cochlear Origin." In Psychophysics and Physiology of Hearing, Evans, E.F. and Wilson, J.P. (eds.), London: Academic Press, 1977 .

Pollack, I., "Effects of High Pass and Low Pass Filtering on the Intelligibility of Speech Sounds," JASA, 20:259-66, 1948.

Priede, V.M. and Coles, R.R.A., "Speech Discrimination Tests in Investigation of Sensorineural Hearing Loss," J. of Laryngol. and otol., 90:1081-92, 1976.

Scharf, B. and Hellman, R.P., "Model of Loudness Summation Applied to Impaired Ears," JASA, 40:71-78, 1966.

Scharf, B. and Meiselman, C.H., "Critical Bandwidth at High Intensities." In Psychophysics and Physiology of Hearing, Evans, E.F. and Wilson, J.P. (eds.), London: Academic Press, 1977.

Scharf, B., "Comparison of Normal and Impaired Hearing I. Loudness, Localization." In Sensorineural Hearing Impairment and Hearing Aids, Ludvigsen, C. and Barford, J. (eds.), Scand. Audiol. Suppl., 6:9-47, 1978..

Sher, A.E. and Owens, E., "Consonant Confusions Associated with Hearing Loss Above 2,000 Hz," JSHR, I7:669-81, 1974.

Simon, G.R., "The Critical Bandwidth Level in Recruiting Ears and its Relation to Temporal Summation," JAR, 3:109-19, 1963.

Thompson, G. and Hoel, R., "Flat' Sensorineural Hearing Loss and PB Scores," JSHD, $27: 284-7,1962$. 
Villchur, E., "Simulation of the Effect of Recruitment on Loudness Relationships in Speech," JASA, 56:1601-11, 1974.

Wightman, F., McGee, T. and Kramer, M., "Factors Influencing Frequency Selectivity in Normal and Hearing-Impaired Listeners." In Psychophysics and Physiology of Hearing, Evans, E.F. and Wilson, J.P. (eds.), London: Academic Press, 1977. 